\title{
COLLABORATION BETWEEN A LECTURER AND LEARNING TECHNOLOGIST TO SUPPORT STUDENT TRANSITION TO AND ENGAGEMENT AND LEARNING IN THE SYNCHRONOUS ONLINE CLASSROOM: HAVING THE BEST OF BOTH WORLDS
}

\author{
Dr Anna Logan ${ }^{1}$, Suzanne Stone ${ }^{2}$ \\ 1 St. Patrick's College, A College of Dublin City University (IRELAND) \\ 2 St. Patrick's College, A College of Dublin City University (IRELAND)
}

\begin{abstract}
The synchronous online classroom is a unique learning space which offers opportunities for exploring new pedagogical approaches in higher education (HE) but also presents many challenges, particularly in transitioning teaching and learning from the face-face to the online learning context. This paper reports the findings of a small-scale study which explored student engagement, interaction and learning in the synchronous online classroom seeking to uncover the affordances and limitations of technological tools to support interaction, teaching and learning. Drawing on data on the perspectives of three voices involved: the lecturer, the student and the learning technologist, the research questions addressed were: What are the experiences and perceptions of students of real time interaction, teaching and learning in the virtual classroom? How can collaboration between a lecturer and learning technologist in the use of pedagogic strategies and technological support facilitate student transition to and engagement in the virtual classroom?
\end{abstract}

A mixed method two-phased approach was used. Phase 1 comprised anonymous online student evaluations and Phase 2 comprised two focus groups one face-to-face and one online with 10 students. Findings from phase 1 suggest that while most participants expressed a preference for the face-to-face classroom, the convenience of the online element was highly salient in enabling them to complete the programme. Some felt that they learned effectively in both contexts and reported that the use of certain strategies enabled them to engage and interact more online than in a face-to-face context. The transition to the online classroom is both cultural and technical and while only a minority of participants require significant technical support many participants will not be familiar with the protocols for attending online classes. Building on Falloon's (2011) conceptual framework, this study suggests that collaboration between a lecturer and a learning technologist can help students develop the technical, procedural and operational knowledge required to make this transition and thus harness the affordances of the online synchronous classroom. Data from phase two will shed further light on student perceptions of engagement and learning to inform the collaborative design and implementation of pedagogical approaches for quality distance learning in the synchronous online classroom.

Keywords: synchronous online classroom, student engagement, learning, collaboration, transition.

\section{1 introduction}

Internationally, as the number and range of online programmes offered in higher education institutions continues to expand, the online synchronous classroom is now commonly used in blended and distance learning courses and is a unique learning space which offers many opportunities for exploring new pedagogical approaches for staff in higher education.

Technological advances over the past decade have provided higher education institutions offering distance education programmes with a much greater range of options with which to communicate and interact with students ([1], Hudson, Knight \& Collins, 2012; McBrien, Jones \& Cheng, 2009). In particular, it has been suggested that Web2 technologies offer the potential to facilitate synchronous interaction. Web-conferencing software, such as Adobe Connect, Big Blue Button, WebEx, Join.me, or iMeet can enable students and lecturers to communicate in real time using live text chat and orally through audio and/or video and to upload and share documents and multimedia resources ([3]). In contrast to asynchronous formats using archived or previously recorded resources and media, synchronous formats enable students to access lectures and interact with the lecturer and their peers 
in real time. However, while it is argued that synchronous interaction can have a positive impact on learning by supporting the types of elements often found in face-to-face contexts (Park \& Bonk, 2007), to date, understanding of how students learn in synchronous contexts is limited ([2]). Previous research ([1]) suggests that many students transitioning from face-to-face to online learning may need particular technical, procedural and operational knowledge. Arguably therefore, supporting students in developing this knowledge is an important consideration for both teaching staff and learning technologists alike.

In this paper the findings of research conducted over two academic years that investigated the experiences and perspectives of staff and postgraduate students using a synchronous online classroom are presented. The study had a particular focus on student engagement, interaction and learning in the synchronous virtual classroom and on the affordances and limitations of technological tools to support engagement, interaction, teaching and learning. In order to contextualise the research, the paper begins with a brief review of literature relating to online and blended learning with a particular focus on the use of synchronous online teaching and learning strategies and on collaboration between a learning technologist and a higher education lecturer. Then the study methodology is outlined, findings of the first phase are presented, then discussed and analysed, and some conclusions are drawn.

\section{LITERATURE REVIEW}

The rapid pace of developments in information and communication technology has not only facilitated distance learning across many disciplines in higher education ([3]) but has been described as "the defining transformative innovation for higher education in the 21st century" (Garrison \& Kanuka, 2004, p. 95). Within teacher education, online learning offers significant potential for accessible, convenient and cost-effective professional development (Fernández, 2007). This may be particularly germane to teacher professional development for inclusive and special education where there may be a shortage of qualified personnel and where access to specialized accredited postgraduate programmes may be problematic, particularly for teachers living in remote rural areas ([2]). In the higher education institution in which the authors work, this need to widen access for teachers living in remote areas in the Republic of Ireland was a significant factor driving the development of blended and online programmes. This lead to, for example, the transitioning to a blended model of the Masters in Special Educational Needs programme which prior to 2013 had been delivered entirely face-to-face on the Dublin city campus.

While blended learning is perhaps most often understood as simply a mix of traditional face-to-face and online teaching, such understandings have been subject to considerable criticism. Interestingly the very use of the term 'blended learning' has been critiqued on the grounds that this simplistic division focused on modes of delivery might be better described as blended teaching or blended pedagogies (Oliver \& Trigwell, 2004). Moreover, commentators have argued for a more integrated understanding which focuses less on comparing modes of delivery whether face-to-face or online, and more on a holistic understanding of how these are combined and integrated to optimise learning ([5]). Cognizant of these concerns, and mindful that teachers are unlikely to adopt technological tools unless they can see the value for student learning (Macdonald \& Campbell, 2012), the authors adopted the definition of blended learning as "learning activities that involve a systematic combination of co-present (face-to-face) interactions and technologically-mediated interactions between students, teachers and learning resources." (Bliuc, Goodyear \& Ellis, 2007, p. 234). This definition is sufficiently complex to support higher education staff in "the necessary process of redefining higher education institutions as being learning centered and facilitating a higher learning experience....and begin to explore the impact of blended learning in achieving more meaningful learning experiences ([5 p. 104]).

Previous studies have argued that insufficient attention has been paid to student perceptions of their blended learning experiences ([9]; Ginns \& Ellis, 2007; López-Pérez, Pérez-López \& Rodríguez-Ariza, 2011). Nevertheless, a recent large-scale quantitative study showed that there is some evidence that factors such as student perceptions of the quality of online teaching and resources used, and higher levels of student interaction were highly salient to student learning outcomes including grades achieved ([10] ) leading the authors to conclude that

teachers in blended learning contexts need to focus not only on the technical capacities and functions of on-line materials and activities, but must also seek to understand their students' 
perceptions of this part of the learning environment, and how successfully that part is in supporting student learning across a whole course (p.63).

Within the literature on online learning, a distinction is often made between asynchronous and synchronous learning environments, the former implying online engagement and interaction from different locations and at different times, and the latter implying such engagement and interaction happening from different locations but at the same time ([6]). Although to date, most research appears to have focused on asynchronous learning environments ([6]; Hrastinski, 2008; [2]), it is perhaps not surprising that with the expansion in the use of web conferencing software which allows students and faculty to interact in real time, there is growing interest in synchronous learning environments. While on the one hand asynchronous interaction may be advantageous in allowing participants ample time for reflection thereby supporting deep learning, synchronous interaction seems to support the development of relationships, dialogue and the exchange of ideas within the learning community ([1], [2]) leading many commentators to conclude that both have a role to play in online learning $([1,12])$. $A$ gap in knowledge and understanding of synchronous online learning has been identified ([1]), leading to calls for studies investigating the kinds of prior knowledge students may require to derive maximum benefit from online learning environments. Fallon (2011 proposes a typology of the areas of knowledge identified "as being critical to student performance in the virtual classroom" [1, p. 448] namely technical knowledge of how to set up, log in and navigate within the live classroom, procedural knowledge of protocols and conventions for online synchronous interaction and operational knowledge of how to best use the available online communication tools such as text chat, microphone, emoticons etc. This conceptual model seems to draw on both technical and pedagogical domains and arguably therefore collaboration between a learning technologist and a higher education teacher should support both partners in working together to identify and develop a deeper understanding of these constructs, and ultimately to better support and enhance student learning in the synchronous online classroom.

In collaborating in the design and delivery of online teaching and learning in undergraduate and postgraduate teacher education programmes over five years both researchers were motivated by a desire to use technological tools in pedagogically appropriate and meaningful ways to support student learning. As a teacher educator and as a learning technologist respectively our perspectives were guided by the principles of social learning theory. Adopting social constructivism as a theoretical framework, and thus viewing learning as shaped by the social context, discourse and collaboration (Vygotsky, 1978), this theoretical perspective influenced the researchers' practice in four important respects. In the first instance, we saw discussion as critical in enabling students to actively and jointly co-construct knowledge and make-meaning and thus in designing online teaching and learning we wished to plan for multiple opportunities for interaction and discussion. Secondly, the module being delivered focused on developing students' conceptual knowledge and understanding of special and inclusive education requiring them to critically reflect on, analyse and evaluate policy, practice and research. Previous experience teaching the module had confirmed that students needed to develop 'threshold concepts' and grapple with 'troublesome knowledge' (Meyer \& Land, 2006, p. 5) which could be best supported through facilitated discussion rather than a teacher-led didactic approach. Logically, it would seem that transitioning these pedagogical approaches to the online environment might be best achieved through a lecturer-learning technologist collaboration underpinned by a shared commitment to a social constructivist approach to teaching and learning. Thirdly, because the development of activities for synchronous online learning has been reported to be time consuming, a collaborative approach to developing such resources has been recommended ([8])and finally, at a personal level we recognised the inherent value of multidisciplinary collaboration and the opportunities this afforded us for our own professional development.

In summary therefore, this paper seeks firstly to make a small contribution to knowledge and understanding of student experience and perceptions of the synchronous online environment and their learning therein, and secondly to explore collaboration between a learning technologist and a lecturer in designing and developing approaches to support synchronous online teaching and learning.

The specific research questions were a) What are the experiences and perceptions of students of real time interaction, teaching and learning in the virtual classroom? b) How can collaboration between a lecturer and learning technologist in the use of pedagogic strategies and technological support facilitate student transition to, engagement, interaction, teaching and learning in the virtual classroom? 


\section{METHODOLOGY}

The specific study context was a two-year part-time Masters' in Special Educational Needs programme delivered using a blended (both face-to-face and online teaching) model. Although both years were blended, year one of the programme was primarily delivered face-to-face with a small number of synchronous live classes. In contrast, year two was chiefly delivered online with twice weekly synchronous online classes throughout the first semester. The research focus was on a taught module delivered primarily in a synchronous online format in the second year. Student participants were 31 qualified primary and post primary teachers working in mainstream and special schools and units. The researchers, a learning technologist and lecturer, were participant researchers in this study.

The module was delivered over an eight-week period, beginning with a series of 12 synchronous online classes each of 90 minutes' duration, two evenings per week, and concluding with a full, sixhour face-to-face day on campus. The platform used was the Adobe Connect web conferencing software. This interface enables the lecturer to share slide presentations, whiteboards or other documents or webpages via screenshare or weblinks. The interactive tools available to students include text chat, two-way audio and video via webcam, and a range of polling applications all of which can be used in the main classroom. The option to create several breakout rooms for small group discussion and activities is also available. The flexibility afforded by Adobe Connect is advantageous in that it enables the lecturer to make adjustments to teaching in response to student needs. All online sessions included a mixture of lecture and online discussion of prior reading or video material in the full group or in small groups using the breakout room function.

A mixed method two-phased approach was used. Phase 1 comprised an anonymous online module evaluation completed in real time at the end of the final (face-to-face) session of the module. Data were collected using the questionnaire activity in Moodle which provided a secure online storage space with each student having access only to their own data. A plain language statement giving information about the research project and inviting participation was provided. The questionnaire included a mixture of fixed response and open questions. Respondents were first asked to indicate whether or not they had used each of the available online tools for interaction in the synchronous online classroom, and then, to use a 5 point Likert scale to rate the impact of each tool on their participation and their learning. Respondents were also asked about the impact of synchronous online interaction on relationship building with the lecturer and their peers, the ease of use of the Adobe Connect interface, the overall balance of the module in terms of pedagogical approaches used and the extent to which they thought the module learning outcomes had been achieved. Finally, they were invited to compare and comment on their engagement and learning in the online and face-toface environment.

Frequencies for responses to the fixed response questions were calculated and are presented in tables. Qualitative responses to open questions were analysed deductively by hand, working from a "start list" of predetermined themes salient to the research questions and theoretical framework (Miles \& Huberman, 1994, p. 58), codes and sub-codes were assigned to sections of the textual responses and as necessary, new codes were created. These data are presented thematically citing illustrative quotations from respondents' answers.

At the time of writing Phase 2 was ongoing and comprised two focus groups of approximately 50 minutes' duration (one face-to-face and one online) with 10 graduates. These provided an opportunity to follow-up the key themes of induction, participation, engagement and learning in the synchronous online classroom and exploring participants' understandings of these. With the permission of participants, focus group data were recorded and transcribed for analysis. In this paper we report data only from Phase 1.

During the delivery of the module and throughout the duration of the study, the researchers met in person regularly at least once per month and also collaborated in reflecting on the literature using the online research tool, Diigo. A dedicated Moodle page situated securely on the Higher Education Authority net server and available only to the named researchers was also used as an online space for reflecting on the data. The study was reviewed and approved by the Research Ethics Committee at the researchers' home institution. 


\section{FINDINGS}

In this section data pertaining to use of specific technological tools and their perceived utility for participation and learning in the synchronous online classroom are first presented after which data relating to building relationships in the online classroom, the overall Adobe Connect interface, and archive are reported in brief. Then, findings relating to the overall balance of pedagogical approaches used and the extent to which respondents felt they had achieved the learning outcomes are reported. Finally, findings regarding respondents' perceptions of their overall engagement and learning in faceto-face and online classes and the comparisons between these are presented.

\subsection{Use and utility of technological tools for participation and learning}

Twenty-seven of the 31 students completed the online questionnaire, giving an overall return rate of $87 \%$. Not all respondents answered each question and the actual number of responses for each question is given where the total is less than 27. The technological tools for interaction were listed as text chat, microphone, poll, webquest and breakout rooms and most respondents had used all five. All of the 26 respondents indicated that they had used the text chat, $25(96 \%)$ had used both the poll and the breakout rooms, and $23(88 \%)$ had used the webquest at least once. Although $22(85 \%)$ had used the microphone, few students used the microphone regularly and it is likely that for many students, the reported use of the microphone may simply represent use during sound checks carried out at induction. Tables 1 and 2 respectively show the respondents ratings, using a five-point Likert scale where $1=$ very useful, $2=$ useful, $3=$ undecided, $4=$ somewhat useful and $5=$ not at all useful, of the utility of each of these tools and of the whiteboard in enabling them to a) participate and b) learn in the synchronous online classroom.

Table 1: Respondents rating of the utility of each tool in enabling them to participate in the synchronous online classroom.

\begin{tabular}{|l|c|c|c|c|c|c|}
\hline $\begin{array}{l}\text { Utility of tool for } \\
\text { PARTICIPATION }\end{array}$ & $\begin{array}{c}\text { very } \\
\text { useful }\end{array}$ & useful & $\begin{array}{c}\text { undecide } \\
\mathrm{d}\end{array}$ & $\begin{array}{c}\text { somewhat } \\
\text { useful }\end{array}$ & $\begin{array}{c}\text { not at all } \\
\text { useful }\end{array}$ & $\begin{array}{c}\text { Total number of } \\
\text { responses }\end{array}$ \\
\hline Text chat & $\begin{array}{c}97 \% \\
(\mathrm{n}=25\end{array}$ & $\begin{array}{c}3 \% \\
(\mathrm{n}=1)\end{array}$ & 0 & 0 & 0 & $\begin{array}{c}100 \% \\
(\mathrm{n}=26)\end{array}$ \\
\hline Microphone & $\begin{array}{c}19 \% \\
(\mathrm{n}=5)\end{array}$ & $\begin{array}{c}46 \% \\
(\mathrm{n}=12 \\
)\end{array}$ & $\begin{array}{c}19 \% \\
(\mathrm{n}=5)\end{array}$ & $\begin{array}{c}12 \% \\
(\mathrm{n}=3)\end{array}$ & $\begin{array}{c}4 \% \\
(\mathrm{n}=1)\end{array}$ & $\begin{array}{c}100 \% \\
(\mathrm{n}=26)\end{array}$ \\
\hline Poll & $\begin{array}{c}85 \% \\
(\mathrm{n}=22)\end{array}$ & $\begin{array}{c}15 \% \\
(\mathrm{n}=4)\end{array}$ & 0 & 0 & 0 & $\begin{array}{c}100 \% \\
(\mathrm{n}=26)\end{array}$ \\
\hline Webquest & $\begin{array}{c}32 \% \\
(\mathrm{n}=8)\end{array}$ & $\begin{array}{c}32 \% \\
(\mathrm{n}=8)\end{array}$ & $\begin{array}{c}20 \% \\
(\mathrm{n}=5)\end{array}$ & $\begin{array}{c}8 \% \\
(\mathrm{n}=2)\end{array}$ & $\begin{array}{c}8 \% \\
(\mathrm{n}=2)\end{array}$ & $\begin{array}{c}100 \% \\
(\mathrm{n}=25)\end{array}$ \\
\hline Breakout Rooms & $\begin{array}{c}35 \% \\
(\mathrm{n}=9)\end{array}$ & $\begin{array}{c}50 \% \\
(\mathrm{n}=13\end{array}$ & $\begin{array}{c}4 \% \\
(\mathrm{n}=1)\end{array}$ & $\begin{array}{c}7 \% \\
(\mathrm{n}=2)\end{array}$ & $\begin{array}{c}4 \% \\
(\mathrm{n}=1)\end{array}$ & $\begin{array}{c}100 \% \\
(\mathrm{n}=26)\end{array}$ \\
\hline Whiteboard & $\begin{array}{c}4 \% \\
(\mathrm{n}=1)\end{array}$ & $\begin{array}{c}9 \% \\
(\mathrm{n}=2)\end{array}$ & $\begin{array}{c}27 \% \\
(\mathrm{n}=6)\end{array}$ & $\begin{array}{c}19 \% \\
(\mathrm{n}=4)\end{array}$ & $\begin{array}{c}41 \% \\
(\mathrm{n}=9)\end{array}$ & $\begin{array}{c}100 \% \\
(\mathrm{n}=22)\end{array}$ \\
\hline
\end{tabular}

These data show that all respondents rated the text chat as either very useful or useful in enabling them to both participate and learn $(100 \%, n=26)$ in the online synchronous classroom. Interestingly, ratings of the usefulness of webquest activities (real time searching for and sharing online resources via text) were also high with $64 \%$ and $68 \%$ rating this as either useful or very useful for participation and learning respectively. Poll ratings were also very high, with all respondents rating this as either very useful or useful for participation (100\%) and learning $(81 \%)$ respectively, while $85 \%$ of respondents rated the breakout rooms as very useful or useful for participation and $66 \%$ rated these as very useful or useful for learning. 
Table 2: Respondents rating of the utility of each tool in enabling them to learn in the synchronous online classroom.

\begin{tabular}{|l|c|c|c|c|c|c|}
\hline $\begin{array}{l}\text { Utility of tool for } \\
\text { LEARNING }\end{array}$ & $\begin{array}{c}\text { very } \\
\text { useful }\end{array}$ & useful & $\begin{array}{c}\text { undecide } \\
\mathrm{d}\end{array}$ & $\begin{array}{c}\text { somewhat } \\
\text { useful }\end{array}$ & $\begin{array}{c}\text { not at all } \\
\text { useful }\end{array}$ & $\begin{array}{c}\text { Total number of } \\
\text { responses }\end{array}$ \\
\hline Text chat & $\begin{array}{c}92 \% \\
(\mathrm{n}=24)\end{array}$ & $\begin{array}{c}8 \% \\
(\mathrm{n}=2)\end{array}$ & 0 & 0 & 0 & $\begin{array}{c}100 \% \\
26\end{array}$ \\
\hline Microphone & $\begin{array}{c}31 \% \\
(\mathrm{n}=8)\end{array}$ & $\begin{array}{c}42 \% \\
(\mathrm{n}=11 \\
)\end{array}$ & 0 & $\begin{array}{c}19 \% \\
(\mathrm{n}=5)\end{array}$ & $\begin{array}{c}8 \% \\
(\mathrm{n}=2)\end{array}$ & $\begin{array}{c}100 \% \\
26\end{array}$ \\
\hline Poll & $\begin{array}{c}50 \% \\
(\mathrm{n}=13)\end{array}$ & $\begin{array}{c}31 \% \\
(\mathrm{n}=8)\end{array}$ & 0 & $\begin{array}{c}19 \% \\
(\mathrm{n}=5)\end{array}$ & 0 & $\begin{array}{c}100 \% \\
26\end{array}$ \\
\hline Webquest & $\begin{array}{c}36 \% \\
(\mathrm{n}=9)\end{array}$ & $\begin{array}{c}32 \% \\
(\mathrm{n}=8)\end{array}$ & $\begin{array}{c}16 \% \\
(\mathrm{n}=4)\end{array}$ & $\begin{array}{c}12 \% \\
(\mathrm{n}=3)\end{array}$ & $\begin{array}{c}4 \% \\
(\mathrm{n}=1)\end{array}$ & $\begin{array}{c}100 \% \\
25\end{array}$ \\
\hline Breakout Rooms & $\begin{array}{c}35 \% \\
(\mathrm{n}=9)\end{array}$ & $\begin{array}{c}31 \% \\
(\mathrm{n}=8)\end{array}$ & $\begin{array}{c}12 \% \\
(\mathrm{n}=3)\end{array}$ & $\begin{array}{c}19 \% \\
(\mathrm{n}=5)\end{array}$ & $\begin{array}{c}3 \% \\
(\mathrm{n}=1)\end{array}$ & $\begin{array}{c}100 \% \\
26\end{array}$ \\
\hline Whiteboard & $\begin{array}{c}18 \% \\
(\mathrm{n}=4)\end{array}$ & $\begin{array}{c}9 \% \\
(\mathrm{n}=2)\end{array}$ & $\begin{array}{c}14 \% \\
(\mathrm{n}=3)\end{array}$ & $\begin{array}{c}4 \% \\
(\mathrm{n}=1)\end{array}$ & $\begin{array}{c}55 \% \\
(\mathrm{n}=12)\end{array}$ & $\begin{array}{c}100 \% \\
22\end{array}$ \\
\hline
\end{tabular}

The data indicates that although the majority of respondents viewed the microphone as useful for both participation and learning, ratings of the utility of this technological tool were somewhat lower overall. Sixty-five per cent of respondents rated the microphone as either very useful or useful for participation, and $73 \%$ of respondents rated this as very useful or useful for participation. This finding is consistent with the limited use of the microphone by comparison with other technological tools for interaction. The high ratings for most tools were in stark contrast to ratings for the use of the whiteboard which were very low, with $60 \%$ and $59 \%$ rating this as either not at all useful or somewhat useful for participation and learning respectively, and a further $27 \%$ and $14 \%$ of respondents undecided about the utility of this tool for participation and learning.

Respondents were asked to indicate to what extent engaging in the online classroom helped them to build relationships with their peers and with the lecturer. The majority of respondents considered that live online engagement was helpful $(50 \%, n=13)$ or very helpful $(27 \%, n=7)$ in building a relationship with the lecturer. In contrast however, as regards building relationship with peers, only $12 \%(n=3)$ rated live online engagement as very helpful with $19 \%(n=5)$ rating this as helpful with the remaining $69 \%$ describing it as somewhat helpful $(38 \%, n=10))$ or unhelpful $(31 \%, n=8)$.

Analysis of the responses to an open question inviting comments on the ease of use of the Adobe Connect platform indicates that 10 adjudged it as very easy to use, with 12 adjudging it as easy, and 5 as quite easy to use. Two respondents specifically mentioned the support they had received from both the learning technologist and lecturer which may indicate awareness among some students at least of this collaboration. Notably, five respondents made reference to occasionally loosing functionality which most attributed to connectivity issues. "I kept getting kicked out of sessions, probably due to my internet connection" (respondent 11), "Occasionally my connection went down and I had to log back in" (respondent 14)

Each live class was recorded and available on Moodle and $80 \%(n=20)$ of the 25 respondents who replied to this question indicated that they had listened to archived sessions. Of these 15 rated listening to the archived recording as very useful with a further 5 rating this as useful. 


\subsection{Balance of pedagogical approaches and achievement of learning outcomes}

When asked their view of the overall balance of pedagogical approaches, 22 of 26 respondents chose to comment on the balance of face-to-face and online sessions with 16 of these expressing a clear preference for more face-to-face sessions. and six describing the balance as appropriate. Of the 16 who wanted more face-to-face sessions, five expressed the view that this allows for more interaction with peers and two cited logistical factors such as balancing online attendance and engagement with other family and home related responsibilities. "The online lectures are hard going, more from a logistical perspective than anything else, trying to get home on time, organise dinner, etc etc, it is very hard going especially on Tuesdays when my school has Croke Park [after school planning] sessions that might last two hours" (respondent 7).

Given that only four respondents commented on other aspects of pedagogy such as assigned reading, this seems to suggest that the face-to-face/online balance may be uppermost in their minds. Notably, despite expressing a preference for more face-to-face sessions, when invited to comment on the extent to which the learning outcomes for the module had been achieved, of the 19 responses that could be categorised, 15 respondents stated that these had been achieved, with a further four considering that these were very well achieved.

\subsection{Perceptions regarding the comparison between engagement and learning in face-to-face and online contexts}

The final two open questions invited respondents to compare the face-to-face and online learning environments in the module asking them to indicate which environment they a) engaged most in and b) learned best in and why. Responses were analysed quantitatively and categorised where possible, and qualitative data were analysed deductively and are presented thematically.

\subsubsection{Student Engagement}

Twenty of the 27 respondents reported that they engaged most in the face-to-face context, four indicated online and three reported that they engaged equally well in both. Analysis of the reasons given suggests five main themes namely; a) interaction/engagement (9), b) discussion of difficult concepts (3), c) connectivity (3), d) distraction (2), and e) communication (2). The numbers in parentheses indicate the number of responses for each theme. Some respondents gave more than one reason which others gave no reason.

Six respondents favoured face-to-face interaction/engagement; "I engaged more in a face to face environment because I felt more involved in the lesson" (respondent 9), "People seem more willing to talk up in face to face sessions and lots of sharing of ideas" (respondent 17).

Nevertheless, three did express a preference for online; "Online probably as everyone can be heard. Can be shy in class" (respondent 27), "Sometimes it is easier online, I probably spoke more on the mic online than I would in class" (respondent 7).

Three respondents cited understanding difficult concepts as reasons for greater engagement face-toface; "It's so much easier to discuss and tease out difficult issues and aspects of the module when the lecturer and your peers are there with you" (respondent 10) and three cited connectivity issues; "Internet and sound issues affected participation for some online" (respondent 16), "online break out rooms were compromised by technology break downs" (respondent 20).

For two respondents, engagement was lower online because of distractions; "you are at home and your eyes wander on to other things that need doing at that time of the evening!" (respondent 5), "I get very distracted at home and zone out" (respondent 26).

Others found communication online to be limiting "few people spoke in breakout rooms online and found lectures could be very monotonous due to lack of face to face stimulation. Communication is only about $7 \%$ verbal. You would really miss the other 93\% :)" (respondent 6).

\subsubsection{Student Learning}

Twenty-one of the 27 respondents indicated that they learned best in the face-to-face context, with three opting for online and three adjudging that they learned equally well in both contexts. Analysis of 
the reasons given suggests four main themes namely; a) interaction/engagement (8), b) distractions (6), c) discussion of difficult concepts (3), and d) convenience/accessibility (2). All 8 respondents who cited interaction/engagement in response to this question felt that interaction in the face-to-face context was more supportive of their learning; "more free flowing discussion and more engaging" (respondent 2), "More willing to ask questions of the lecturer" (respondent 16); "Both involved learning, but on campus has the added dimension of learning from classmates" (respondent 17). Interestingly, six respondents cited distraction as a reason for learning better face-to-face "Think its because I'm physically in the moment with no distractions of cookers or pots to be stirred" (respondent 4), "I definitely find I learn more in face to face lecture, it's hard to stay focused when there are distractions around" (respondent 26). For two respondents face-to-face was the preferred context for discussion of difficult concepts; "Face-to-face. It allows for freer discussion and thrashing out of issues" (respondent 11). However, two respondents reported learning better online than in the face-to-face context for reasons of convenience and accessibility; "Overall the online classroom because it was so easily accessible! I missed a lecture and could catch up online! If face to face I would have missed altogether?' (respondent 3), "Online, the facility to listen back is great and the text chat is a whole bank of resources. For face to face I find I am rushing to write everything down and be sure I haven't missed anything" (respondent 12).

\section{DISCUSSION}

In this section, the findings reported above regarding student perception of engagement and learning in a synchronous online classroom and regarding lecturer-learning technologist collaboration are discussed and analysed in terms of the research questions posed and the literature reviewed.

\subsection{What are the experiences and perceptions of students of real time interaction, teaching and learning in the virtual classroom?}

The majority of participants in this study made use of many of the tolls for interaction available in the synchronous online classroom, rating most as useful in supporting their online participation and learning. In the main, somewhat higher levels of satisfaction were reported for text based tools such as text chat, polls and the webquest activity than for applications which required participants to interact using the microphone. Previous studies have indicated that participants in live online learning environments may value having the time to think about and edit text contributions and that high levels of text chat benefits interactivity [6]. The webquest activity used in the current study was an adaptation of the use of the text chat box for a specific purpose and the success of this strategy lends support to an earlier recommendation that lecturers using text chat should consider setting goals to structure the discussion [6]. Extensive use was also made of the polling application to set true/false, multiple choice and short answer questions and virtually all students participated in all polls. The high levels of engagement could be attributable to the fact that most polls were anonymous which is likely to encourage participation [2]. From the lecturer's perspective, another advantage of polling over text chat is that when results are broadcast all the data is displayed in a well-structured and coherent manner, making the information readily accessible and understandable to both lecturer and students.

Overall, while most expressed a preference for the face-to-face classroom, the convenience of the online element was highly salient in enabling many participants living at a distance from the city campus to complete the programme. Participants appreciated the use of strategies to support their engagement and learning "I think excellent use was made of the technology available. Break out rooms were a fantastic tool and they really made the online lectures far more engaging" (respondent 19). Over time it was apparent that participants began to utilise and recognise the value of using online tools for interaction "I felt that we (as a group) got more confident online though and got better at talking on the mic and coping with the breakout rooms" (respondent 23).

Finally, the low levels of satisfaction with the whiteboard application could be attributable to the fact that the authors had insufficient time for collaborative planning and trialling of this application. This finding supports previous studies indicating that sufficient time and a systematic approach is required to develop online activities for synchronous tools [2]. Arguably, this may be best achieved through collaboration between lecturers and the learning technologists with whom they work.

\subsection{How can collaboration between a lecturer and learning technologist in the use of pedagogic strategies and technological support facilitate student}




\section{transition to, engagement, interaction, teaching and learning in the virtual classroom?}

In considering our collaboration as a lecturer and a learning technologist, we have used Falloon's (2011) theoretical framework of the technical, procedural and operational knowledge which he contends that students need to have to benefit fully from the synchronous online classroom to audit and evaluate our collaborative efforts. Regarding technical knowledge of how to set up, log in and navigate within the virtual classroom, we jointly planned and delivered a face-to-face demonstration of the interface and applications and a live online soundcheck prior to the commencement of the online modules. To date, this has been sufficient for most students although a small number of students may need additional support during the initial synchronous classes. In such cases it helpful for the learning technologist to be present for the first 15 to 20 minutes of the classes to provide technical support to these students via text chat thus enabling the lecturer to proceed with the learning content and crucially protect the integrity of the time available for online teaching and learning.

We trace our awareness of the importance of students having operational knowledge of how to best use the range of communication tools available in the synchronous classroom to difficulties we encountered when using breakout rooms for the first time. Although a soundcheck had been conducted at the start of the module, only a minority of participants had used the mic regularly, many were reticent about speaking and consequently the planned group discussion did not materialise. Together we identified the gaps in students' operational knowledge e.g. of how to turn on and mute the mic, how to use text chat, take notes and use the whiteboard, and we jointly developed strategies to address these such as displaying the breakout room layout in the main room prior to the breakout session and explicitly drawing students' attention to the differences in functionality in the main room and in breakout rooms.

It is in regard to identifying and addressing gaps in procedural knowledge of the conventions and protocols for synchronous online learning that collaboration between lecturers and learning technologists has perhaps the greatest potential contribution to make. This knowledge is perhaps more difficult to define than technical or procedural knowledge but is no less important. We have found for example that utilising video material demonstrating the pitfalls of failing to be mindful of timekeeping and turn-taking, and the need to show courtesy to other participants and to take personal responsibility has been very effective in raising student awareness.

\section{CONCLUSIONS}

This research was timely, enabling rigorous study of online engagement and learning of and with teachers across the education continuum and providing a valuable context for professional development opportunities for both participants and researchers. Additionally, the collaborative interdisciplinary nature of the study enabled reflection on and analysis of the collaborative partnership of learning technologist and lecturer in enabling and facilitating student engagement and learning. Nevertheless, this was a small-scale study based on data pertaining to one cohort of 31 postgraduate students completing a module as part of a masters programme and a lecturer and a learning technologist as participant researchers. As such, the findings cannot be considered generalizable in any way. Instead, we present our findings for consideration by other higher education staff involved in the design and delivery of blended learning with similar student cohorts in synchronous online classrooms.

In summary, notwithstanding the small-scale and context specific nature of the research, this study confirms the findings of previous research which identifies benefits of synchronous online interaction for student engagement and learning [1,3].). We focused on an aspect recognised as having received insufficient attention to date, namely student perceptions and evaluations of their online engagement and learning, $[9,10,11]$. Gathering and systematically analysing these data has shed further light on student perceptions of engagement and learning and enabled us to use this to inform the collaborative design and implementation of pedagogical approaches for quality distance learning in the synchronous online classroom.

It is suggested that collaboration between lecturer, learning technologist and students can facilitate participants in developing the technical, procedural and operational knowledge required to make this transition and thus harness the affordances of the online synchronous classroom. Data from phase two will shed further light on student perceptions of engagement and learning in the online classroom. 


\section{REFERENCES}

[1] Falloon, G. (2011b). Exploring the Virtual Classroom: What Students Need to Know (and Teachers Should Consider, MERLOT Journal of Online Learning and Teaching 7(4), pp. 439451.

[2] Hudson, T., Knight, B. \& Collins, V. (2012). Perceived Effectiveness of Web Conferencing Software in the Digital Environment to Deliver a Graduate Course in Applied Behavior Analysis. Rural Special Education Quarterly, 31(2), pp.27-39.

[3] McBrien,J., Jones, P., \& Cheng, R. (2009). Virtual Spaces: Employing a Synchronous Online Classroom to Facilitate Student Engagement in Online Learning, International Review of Research in Open and Distance Learning, 10(3), pp. 1-17.

[4] Park, Y. \& Bonk, C. (2007). Synchronous Learning Experiences: Distance and Residential Learners' Perspectives in a Blended Graduate Course, Journal of Interactive Online Learning, 6(3), pp. 245-264.

[5] Garrison, R. \& Kanuka, H. (2004) Blended Learning: Uncovering its Transformative Potential in Higher Education, The Internet and Higher Education 7, pp. 95 - 105.

[6] Fernández, M. (2007) Communication and Instruction in an Online Graduate Education Course, Teaching Education, 18(2), 137-150.

[7] Oliver, M., \& Trigwell, K. (2005). Can 'Blended Learning' be Redeemed? E-learning, 2(1), pp.17-26.

[8] Macdonald, J., \& Campbell, A. (2012). Demonstrating online teaching in the disciplines. A systematic approach to activity design for online synchronous tuition. British Journal of Educational Technology, 43(6), pp. 883-891.

[9] Bliuc, A., Goodyear, P. \& Ellis, R. (2007) Research Focus and Methodological Choices in Studies into Students' Experiences of Blended Learning in Higher Education, The Internet and Higher Education, 10, pp. 231-244.

[10] Ginns, P., \& Ellis, R. (2007). Quality in Blended Learning: Exploring the Relationships between On-line and Face-to-face Teaching and Learning, The Internet and Higher Education 10, pp. 53-64.

[11] López-Pérez, M., Pérez-López, M., \& Rodríguez-Ariza, L. (2011). Blended Learning in Higher Education: Students' Perceptions and their Relation to Outcome, Computers and Education, 56(3), pp. 818-826.

[12] Hrastinski, S. (2008). Asynchronous and Synchronous E-Learning: A study of asynchronous and synchronous e-learning methods discovered that each supports different purposes. EDUCAUSE Quarterly, 31(4), pp. 51-55.

[13] Vygotsky, L. (1978). Mind in Society: The Development of Higher Psychological Processes. Harvard University Press, Cambridge, MA.

[14] Meyer, J. \& Land, R. (2006). Threshold Concepts and Troublesome Knowledge: An Introduction. In J. H. F. Meyer \& R. Land (Eds), Overcoming Barriers to Student Understanding: Threshold Concepts and Troublesome Knowledge (pp. 3-18). London: Routledge.

[15] Miles, M., \& Huberman, A. (1994). Qualitative data analysis: an expanded sourcebook ( ${ }^{\text {nd }}$ ed.). London: Thousand Oakes. 